\title{
Validation of A Lebanese Arabic Version of the Oswestry Disability Index in Lebanon
}

\author{
Chakib Ayoub ${ }^{1}$, Elias Elias ${ }^{2}$, Zeina Nasser ${ }^{3}$, Rosemary Khoury $^{2}$ MPH and Ghassan Skaf ${ }^{2 *}$ \\ ${ }^{1}$ Department of Anesthesiology, American University of Beirut Medical Center, Lebanon
}

${ }^{2}$ Department of Neurosurgery, American University of Beirut Medical Center, Lebanon

${ }^{3}$ Research Center in Epidemiology, Biostatistics and Clinical Research, Université Libre de Bruxelles, Belgium

Submission:December 12, 2018; Published: March 15, 2019

*Corresponding author: Ghassan Skaf, Division of Neurosurgery, Department of Surgery, American University of Beirut Medical Center, Riad El Solh, 1107-2020, Beirut, Lebanon

Abstract

Objective Oswestry Disability Index is the most commonly used score for assessing spinal disorders disabilities. However, no validated Lebanese version of the index was available till the time of initiation of our study. Our aim is to validate and adapt the Saudi Arabia version of the Oswestry Disability Index among the Lebanese population.

Methods: After a cultural adaptation of the Arabic questionnaire, a pilot study was conducted to assess the comprehensibility of the prefinal version. The Lebanese version was tested on 96 patients suffering from low back pain who were assessed by phone call twice within 2 weeks. Internal consistency, test-retest reliability, convergent and discriminant validity were investigated.

Result: The Cronbach's alfa for the Oswestry Disability Index was 0.87. Factor analysis revealed the presence of one component with eigenvalue exceeding 1, explaining 68\% of the variance. The correlation of the Oswestry Disability Index with the Quebec Back Pain Disability Scale and the Roland-Morris Disability questionnaire was $0.97,0.95$ respectively $(\mathrm{P}<0.001)$. The Oswestry Disability Index showed excellent test-retest reliability.

Conclusion: The Lebanese Version of the Oswestry Disability Index is reliable and valid tool to assess the functional ability among the Lebanese-speaking population with Low Back Pain.

Keywords: Oswestry Disability Index; Roland Morris Disability; Questionnaire; Quebec back pain; Disability Scale; Low Back Pain; Lebanese population; Validation

Abbrevations: LBP: Low Back Pain; RMQ: Roland Morris Disability Questionnaire; ODI: Oswestry Disability Index; QMS: Quebec back pain Disability Scale; RMDQ: Roland-Morris Low Back Pain Disability; SPSS: Statistical Package for Social Sciences; ICC: Intra-Class Correlation

\section{Introduction}

Low Back Pain (LBP) is one of the most common causes of work absenteeism [1,2]. Its prevalence reaches $15 \%$ to $30 \%$ among adult population [3]. Self-reported questionnaires are usually applied to evaluate the pain condition, effects on daily life activities and as a measuring tool for outcome whenever subjects undergo medical or surgical intervention. Most popular and widely used assessment tools are the Oswestry Disability Index (ODI) [4-6], Roland Morris Disability Questionnaire (RMQ) and the Quebec back pain Disability Scale (QMS) [7,8]. Largely, these questionnaires were established to survey English speaking populations.

The surge of multicultural research studies precipitated the need to adapt health status measures for use in languages other than the source language. However, questionnaires cannot be applied directly from one social environment to another by a simple direct translation without validation [9], mainly due to the variability of disease expression between diverse non-English speaking subjects and in order to accomplish a comparable questionnaire that permits resemblance of data. So far, ODI was validated into different versions, such as German, Spanich, Chinese, Italian [10-13]. but no Lebanese version have been validated till this date. Our aim is to validate and adapt the Saudi Arabia version of the ODI among the Lebanese population.

\section{Materials and Methods}

\section{Study participants}

The study was conducted on 96 adult patients suffering from low back pain who presented to the American University of Beirut 
between Jan 2012 and Jan 2014. The number of participants met the preferred sample size of 5-10 times patients per item for performing exploratory factor analysis [14]. Participants eligible for the study had to satisfy the following inclusion criteria: age must be 18 years or older of either gender, could speak and read the Arabic language, and suffering from low back pain. Exclusion criteria were psychiatric diseases, pregnant women, nursing mothers and subjects who are unable to provide informed consent. Local Ethics Committees approval was obtained from the institutional review board of the American University in Beirut.

\section{The Oswestry Disability Index (ODI)}

The ODI is a tool designed and used by clinicians to assess and quantify disabilities associated with low back pain. It was published by Fairbank et al. [5]. This index is composed of 10 items, each inclosing six questions scored from a scale of zero to five. Main categories of the 10 items are classified from 1 to 10 in the following way: Pain intensity, personal care, lifting, walking, sitting, standing, sleeping, sexual life, social life and travelling. Calculation is done in terms of percentage by dividing the total by 50 and multiplying it by 100 once the score is obtained. It ranges from a zero percent (which refers to no disability) reaching 100 $\%$ (which refers to total disability). Scores from 0 to $20 \%$ are categorized under minimal disability; Scores from 20 to $40 \%$ signify moderate disability; Scores from 40 to $60 \%$ means severe disability; Scores from 60 to $80 \%$ refer to crippling low back pain and scores beyond $80 \%$ denote an excessive incapacity. Items of the ODI scale has been translated and adapted to the Arabic language in Saudi Arabia [15]. A review committee (two Neuro-surgeons and two epidemiologists) compared the validated Arabic version with the original English version to detect misinterpretations and nuances that might have been missed. This committee discussed translation procedure until a consensus was reached on discrepancies. The Lebanese dialect is slightly different from the Saudi and Tunisian one, so the term referring to pain in Arabic "aalaam" was substituted with "wagaa" after consensus between committee members. The prefinal version of the ODI questionnaire was then pilot tested in a sample of 30 patients ( 15 males and 15 females) to check the clarity and readability of all items. Each patient was asked to identify any words that were difficult to understand. In addition, the investigator was asked to document any problems that occurred during the administration of the questionnaire. Most of the 30 patients considered section 8 (Sex life) in the ODI translated score as a social taboo, so we decided to omit this question in the final Lebanese version.

\section{Procedure}

Ninety-six eligible patients provided an informed consent. One investigator extracted data regarding socio-demographic characteristics (age, gender, marital status, level of education and smoking status), body weight and height, clinical data (presence of chronic disease) and the 9-item ODI questionnaire. In addition, the Roland-Morris Low Back Pain Disability (RMDQ) and the score of the Quebec Back Pain Disability Scale (QDS) were used for convergent validation. The 9-items ODI questionnaire were read loud and repeated but not modified by the investigator. On average, the questionnaire was completed by participants within approximately 4 minutes. To assess test-retest reliability of the scale, all the participants answered the questionnaire two times. The time between test and re-test reproducibility examination averaged approximately 2 weeks.

\section{Assessment measures}

The Roland-Morris Low Back Pain Disability (RMQ): The RMQ consists of 24 items related to normal activities of daily living. Each answer is scaled simply 0 or 1 , allotting a range of scores of 0 to 24, a higher score indicating higher disability [7].

The Quebec Back Pain Disability Scale (QDS): The QDS is a 20 -item questionnaire where the subject is told to answer each question on a scale, for each activity there is a scale of 0 to 5 . The final outcome is obtained by the sum of the scoring of the degree of difficulty in performing the 20 daily activities. These outcomes score within the range of 0 and 100, with higher numbers representing greater levels of disability [16].

\section{Statistical analysis}

Data entry and analysis were performed using Statistical Package for Social Sciences (SPSS) version 22. Descriptive statistics mainly means were used for continuous variables while percentages were presented for categorical variables. Cronbach's alpha test was used to assess the internal consistency of the total scale. A coefficient $>0.7$ indicated a good internal consistency. Test-retest reliability was assessed through the Intra-Class Correlation coefficient (ICC; average measure) item per item and for the global scale. A good reproducibility was noted when ICC $>0.7$. Prior to an exploratory factor analysis, the suitability of data was assessed by the Kaiser-Meyer-Olkin statistic of sampling adequacy and Bartlett's sphericity test. Factor analysis was performed using the principal components analysis to extract factors. The retained factor had eigenvalues of over 1. Independent factors were obtained using the varimax rotation method. Convergent validity was assessed by Spearman's rank correlations to evaluate whether total OSD scale were associated with the score of the Roland-Morris Low Back Pain Disability (RMDQ) and the score of the Quebec Back Pain Disability Scale (QDS). The results were interpreted as follows: excellent relationship $r>0.91$, good $0.71-0.9$, moderate $0.51-0.7$, poor $0.31-0.5$, very poor or null $r<0.3$. A P-value (twotailed) of $<0.05$ was considered statistically significant.

\section{Results}

\section{Baseline Characteristics of the participants}

The study included 96 patients, 51\% male and 49\% female. The mean age was $67.03 \pm 11.13$ years. The majority of our patients was married (92.7\%) and educated at school for 


\section{Open Access Journal of Neurology \& Neurosurgery}

more than 12 years (82.3\%). Additional socio-demographic characteristics of the enrolled population are described in Table 1.

Table 1: Socio-demographic and clinical characteristics of the participants.

\begin{tabular}{|c|c|}
\hline Characteristics & All Patients ( $(\mathrm{N}=96) \mathrm{n}(\%)$ \\
\hline Age (Mean $\pm \mathrm{SD}^{*}$ ) & 67.03(11.13) \\
\hline \multicolumn{2}{|c|}{ Gender } \\
\hline Male & $49(51)$ \\
\hline Female & $47(49)$ \\
\hline \multicolumn{2}{|c|}{ Marital status } \\
\hline Married & $89(92.7)$ \\
\hline Other† & $7(7.3)$ \\
\hline \multicolumn{2}{|c|}{ Education level } \\
\hline$<12$ years & $17(17.7)$ \\
\hline$>12$ years & $79(82.3)$ \\
\hline \multicolumn{2}{|c|}{ Smoking status } \\
\hline No & $62(64.6)$ \\
\hline Yes & $34(35.4)$ \\
\hline \multicolumn{2}{|c|}{ Presence of chronic diseases } \\
\hline Dyslipidemia & $47(49)$ \\
\hline Diabetes & $21(21.9)$ \\
\hline $\begin{array}{l}\text { Coronary artery } \\
\text { disease (CAD) }\end{array}$ & $9(9.4)$ \\
\hline BMI (Mean \pm SD*) & $27.68(4.32)$ \\
\hline
\end{tabular}

Mean values are presented with their Standard Deviation (SD), and frequencies in numbers $(n)$ and percentage $(\%) \dagger$ Single, widowed and divorced

‡BMI: Body Mass Index

*SD: Standard deviation.

\section{Factor analysis}

Table 2: Factor analysis of the Oswestry Disability Index and varimax rotation.

\begin{tabular}{|c|c|c|}
\hline Items & Loading on factor & Communalities \\
\hline Pain Intensity & 0.92 & 0.85 \\
\hline Personal Care & 0.78 & 0.6 \\
\hline Lifting & 0.82 & 0.67 \\
\hline Walking & 0.84 & 0.69 \\
\hline Sitting & 0.87 & 0.75 \\
\hline Standing & 0.76 & 0.58 \\
\hline Sleeping & 0.78 & 0.5 \\
\hline Social Life & 0.87 & 0.75 \\
\hline Traveling & 0.87 & 0.77 \\
\hline
\end{tabular}

Exploratory factor analysis was performed including the 9 items of the ODI scale. The Kaiser-Meyer-Olkin statistic of sampling adequacy exceeded $0.5(\mathrm{KMO}=0.91)$ and Bartlett's sphericity test was statistically significant $\left(\chi^{2}=721.9, \mathrm{df}=36\right.$, $\mathrm{p}$-value $<0.001$ ) indicating that the samples met the criteria for factor analysis. Principal component factor analysis revealed the presence of one component with eigenvalue exceeding 1 , explaining $68 \%$ of the variance. The reliability analysis showed a high Cronbach alpha of 0.87 . Table 2 displays the factor loadings and communality for each item.

\section{Test- retest reliability}

The results of the test-retest reliability assessment demonstrated strong reproducibility of the ODI scales [Intraclass correlation $(95 \% \mathrm{CI})$ : overall scale, ICC $=0.975(0.964$ $0.981)$, P-value $<0.001$. Item per item reproducibility showed an excellent correlation coefficient ranging from 0.893 to 0.974 (Table 3).

Table 3: Test-retest reliability of the ODI scale $(\mathrm{N}=96)$ is expressed by intraclass correlation coefficient (ICC). ODI Owestry Disability Index, ${ }^{*} \mathrm{P}$-value $<0.05$ significant.

\begin{tabular}{|c|c|c|}
\hline Item & $\begin{array}{c}\text { Intra class corré- } \\
\text { lation } \\
\text { coefficient (95\%CI) }\end{array}$ & P-value \\
\hline Pain Intensity & $0.966(0.941-0.972)$ & $<0.001^{*}$ \\
\hline Personal Care & $0.893(0.851-0.924)$ & $<0.001^{*}$ \\
\hline Lifting & $0.974(0.968-0.988)$ & $<0.001^{*}$ \\
\hline Walking & $0.901(0.862-0.929)$ & $<0.001^{*}$ \\
\hline Sitting & $0.918(0.885-0.941)$ & $<0.001^{*}$ \\
\hline Standing & $0.959(0.942-0.972)$ & $<0.001^{*}$ \\
\hline Sleeping & $0.895(0.776-0.901)$ & $<0.001^{*}$ \\
\hline Social Life & $0.959(0.878-0.971)$ & $<0.001^{*}$ \\
\hline Traveling & $0.966(0.941-0.972)$ & $<0.001^{*}$ \\
\hline Score global & $0.975(0.964-0.981)$ & $<0.001^{*}$ \\
\hline
\end{tabular}

\section{Convergent validity}

The correlations of our index with the Quebec Back Pain Disability Scale (QDS) ( $\mathrm{r}=0.97, \mathrm{P}<0.001)$ and the Roland-Morris Low Back Pain Disability $(\mathrm{r}=0.95, \mathrm{P}<0.001)$ were deemed excellent. The ODI has a good convergent validity (Figures 1-2).

\section{Discussion}

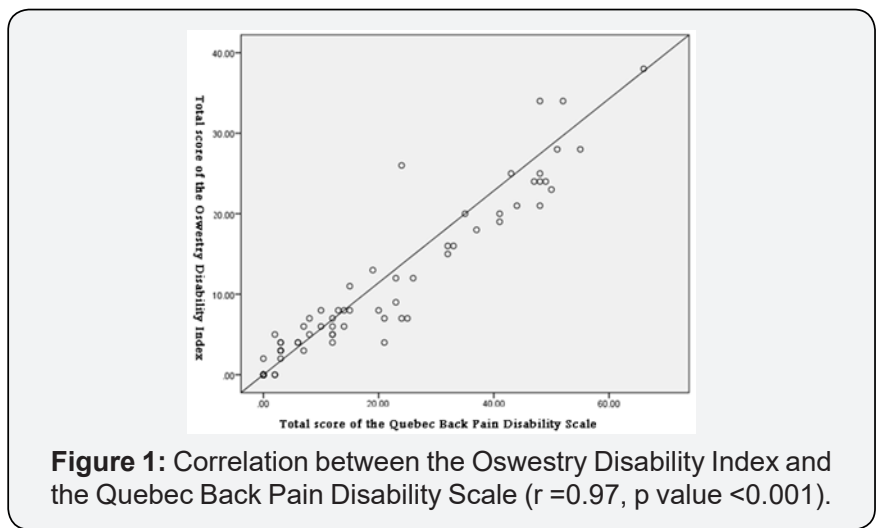




\section{Open Access Journal of Neurology \& Neurosurgery}

The aim of our study was to evaluate the psychometric properties of the Lebanese version of the ODI. Our data demonstrate that it exhibits good psychometric properties regarding reliability, internal consistency, and construct validity which is similar to the results of the Saudi Arabian ODI [17]. The questionnaire revealed to be highly comprehensible by Lebanese population, requiring only few minutes to be completed, with a mean time of 3.8 minutes, a period similar to the mean time needed to complete the ODI in other languages $[15,17]$. The sex life question in section 8 was omitted in our version to avoid low rate response to the sex life question. This question is part of social taboo in Lebanon that can't be discussed freely with the patients. The same step took place in the final Korean version where they also omitted the sex life question in section 8 [18].

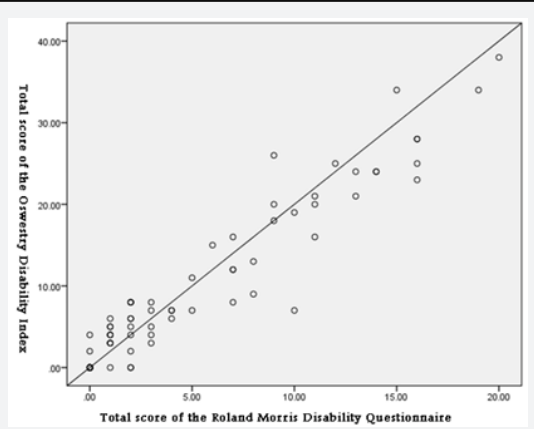

Figure 2: Correlation between the Oswestry index and the Roland-Morris Low Back Pain Questionnaire ( $r=0.95$, $p$ value $<0.001)$.

The Cronbach's alpha test of the ODI was 0.87 , similar to values reported in other papers suggesting a good internal validity $[11,13,19,20]$. Other findings are indicative of good test-retest reliability. Our study also provide evidence for the construct validity of the ODI which reveals statistical significance and positive associations with similar constructs such as the Quebec Back Pain Disability Scale (QDS) and the Roland-Morris Disability questionnaire (RMQ). These results were consistent with previous study conducted by A.S. Algarni et al in KSA that used the QDS and RMQ to evaluate the construct validity of the Saudi Arabian ODI [17]. These findings provide strong evidence in support of the fact that the ODI is a valid measure that evaluates the functions of patients with LBP.

The limitations of the current study include a risk of selection bias, since the sample was not randomly selected. Our samples included only elderly adults recruited from the American University of Beirut Medical Center; the validation findings may not be generalizable to adults in Lebanon of different socioeconomic or regional backgrounds. Future studies should examine the psychometric properties of the scale with a more diverse sample. We have also validated the new scale against a set of measures that have not been validated in Lebanon. However, nothing could have been done to overcome this problem since no validated tools exist in Lebanon. Further research would be required to discuss the ability of the instrument to detect change over time as a function of clinical intervention. Despite these limitations, this article is the first trial to evaluate the functional limitation in LBP in Lebanon. It should help researchers and clinicians to measure the outcome before and after the treatment.

\section{Conclusion}

The Lebanese version of the ODI proved to be reliable, valid and adequate tool to assess the disability in Lebanese patients with low back pain. We recommend the use of this Lebanese version of ODI in clinical practice and scientific research on Lebanese speaking patients who present with low back pain.

\section{Conflict of Interest}

The authors of the manuscript certify that they have NO affiliations with or involvement in any organization or entity with any financial interest or non-financial interest in the subject matter or materials discussed in this manuscript. The authors declare no conflict of interest.

\section{References}

1. Hagen KB, Thune $O$ (1998) Work incapacity from low back pain in the general population. Spine (Phila Pa 1976) 23(19): 2091-2095.

2. Merkesdal S, Mau W (2005) Prediction of costs-of-illness in patients with low back pain undergoing orthopedic outpatient rehabilitation. Int J Rehabil Res 28(2): 119-26.

3. Grabois M (2005) Management of chronic low back pain. Am J Phys Med Rehabil 84(3 Suppl): S29-41.

4. Fritz JM, Irrgang JJ (2001) A comparison of a modified Oswestry Low Back Pain Disability Questionnaire and the Quebec Back Pain Disability Scale. Phys Ther 81(2): 776-788.

5. Fairbank JC, Couper J, Davies JB, O Brien JP (1980) The Oswestry low back pain disability questionnaire. Physiotherapy 66(8):271-273.

6. Fairbank JC, Pynsent PB (2000) The Oswestry Disability Index. Spine (Phila Pa 1976) 25(22): 2940-2952.

7. Roland M, Morris R. (1983) A study of the natural history of back pain. Part I: development of a reliable and sensitive measure of disability in low-back pain. Spine (Phila Pa 1976) 8(2): 141-144.

8. Kopec JA, Esdaile JM, Abrahamowicz M, Abenhaim L, Wood-Dauphinee S, et al. (1995) The Quebec Back Pain Disability Scale. Measurement properties. Spine (Phila Pa 1976) 20(3): 341-352.

9. Beaton DE, Bombardier C, Guillemin F, Ferraz MB (2000) Guidelines for the process of cross-cultural adaptation of self-report measures. Spine (Phila Pa 1976) 25(24): 3186-3191.

10. Mannion AF, Junge A, Fairbank JC, Dvorak J, Grob D (2006) Development of a German version of the Oswestry Disability Index. Part 1: crosscultural adaptation, reliability, and validity. Eur Spine J 15(1): 55-65.

11. Payares K, Lugo LH, Morales V, Londono A (2011) Validation in Colombia of the Oswestry disability questionnaire in patients with low back pain. Spine (Phila Pa 1976) 36(26): E1730-17355.

12. Liu H, Tao H, Luo Z (2009) Validation of the simplified Chinese version of the Oswestry Disability Index. Spine (Phila Pa 1976) 34(11): 12111216.

13. Monticone M, Baiardi P, Ferrari S, Foti C, Mugnai R, et al. (2009) Development of the Italian version of the Oswestry Disability Index 
(ODI-I): A cross-cultural adaptation, reliability, and validity study. Spine (Phila Pa 1976) 34(19): 2090-2095.

14. Streiner DL (1994) Figuring out factors: the use and misuse of factor analysis. Can J Psychiatry 39(3): 135-140.

15. Mousavi SJ, Parnianpour M, Mehdian H, Montazeri A, Mobini B (2006) The Oswestry Disability Index, the Roland-Morris Disability Questionnaire, and the Quebec Back Pain Disability Scale: translation and validation studies of the Iranian versions. Spine (Phila Pa 1976) 31(14): E454-459.

16. Kopec JA, Esdaile JM, Abrahamowicz M, Abenhaim L, Wood-Dauphinee S, et al. (1996) The Quebec Back Pain Disability Scale: conceptualization and development. J Clin Epidemiol 49(2): 151-161.
17. Algarni AS, Ghorbel S, Jones JG, Guermazi M (2014) Validation of an Arabic version of the Oswestry index in Saudi Arabia. Ann Phys Rehabil Med 57(9-10): 653-663

18. Kim DY, Lee SH, Lee HY, Lee HJ, Chang SB, et al. (2005) Validation of the Korean version of the oswestry disability index. Spine (Phila Pa 1976) 30(5): E123-127.

19. Valasek T, Varga PP, Szoverfi Z, Kumin M, Fairbank J, Lazary A (2013) Reliability and validity study on the Hungarian versions of the oswestry disability index and the Quebec back pain disability scale. Eur Spine J 22(5): 1010-1018.

20. Kim HJ, Suh BG, Lee DB, Park JY, Kang KT, et al. (2013) Gender difference of symptom severity in lumbar spinal stenosis: role of pain sensitivity. Pain physician 16(6): E715-723.

\section{Your next submission with Juniper Publishers will reach you the below assets}

- Quality Editorial service

- Swift Peer Review

- Reprints availability

- E-prints Service

- Manuscript Podcast for convenient understanding

- Global attainment for your research

- Manuscript accessibility in different formats

( Pdf, E-pub, Full Text, Audio)

- Unceasing customer service

Track the below URL for one-step submission https://juniperpublishers.com/online-submission.php 